\title{
Aspects of potassium and magnesium uptake by oats
}

\author{
A. C. Schuffelen \\ Department of Soils and Fertilizers, Agricultural University, Wageningen, \\ the Netherlands
}

\begin{abstract}
Summary
Data from a number of experiments indicate that the occurrence of magnesium shortage is only slightly directly related to the acidity of the medium. It is calculated that about $3 \%$ of the total uptake mechanism for potassium and magnesium consists of a specific mechanism for the magnesium uptake, some $30 \%$ is formed by a specific mechanism for the uptake of potassium, while the remaining $67 \%$ is formed by a common mechanism. It is not clear whether this mechanism comprises one or more systems, because both the corrections applied to concentrations at the surface of the root and to the root potential could point in the direction of a presence of one mechanism. At very low potassium concentrations, the specific potassium uptake mechanism may also take up sodium.
\end{abstract}

\section{Introduction}

Soon after my arrival in Wageningen in $1930 \mathrm{I}$ got acquainted with the 'Hooghalen' disease. Hudig, who had already in 1916 described this soil-borne disease at it occurred in the Netherlands (Hudig \& Jonker, 1916), assumed that its occurrence was due to the high acidity (low $\mathrm{pH}$ value) of the soils. An incorrect ratio between $\mathrm{H}, \mathrm{Mg}$ and $\mathrm{Ca}$ ions would adversely affect the magnesium status within the plant. This would lead to mottling of the leaves and in severe cases to decreases of yield.

About 1935, in a field trial at Ruurlo, it was observed that by application of ordinary potash fertilizers it was impossible to create the desired increase of potassium levels in the soil. Cleveringa was then advised to try potassium corbonate. After application of this alkaline fertilizer the oat crop showed very pale discolorations which were initially ascribed to iron deficiency. Leaf analysis showed, however, that in this case magnesium shortage was also to be considered. These Ruurlo symptoms were found to be a variant of the Hooghalen disease and were here caused by excessive amounts of potassium. This disease occurs when the ratio between the ions $\mathrm{H}-\mathrm{Ca}-\mathrm{Mg}$ and $\mathrm{K}$ is incorrect.

The effects of different ratios between the ions on their uptake and on the development of crops from a very difficult subject to study in field experiments, because of the difficulty in defining the exact composition of the growth medium.

Therefore, soon the system of pot experiments was introduced for the study of these effects, whereby artificial soils were used as a substratum for growth. The product 'Dusarite' - a sulphonated fat coal used for demineralization of water in the 1930's was chosen for this purpose. Monoionic complexes were prepared of this cation-exchanging material ( $\mathrm{H}$-dusarite, $\mathrm{K}$-dusarite, $\mathrm{Mg}$-dusarite etc.), and by mixing the different monoionic complexes, it was possible to introduce a large variety of ratios between the H-K-Mg-Ca-Na ions (Schuffelen, 1940). 
Table 1. Review of experimental treatments.

\begin{tabular}{|c|c|c|c|c|c|c|}
\hline & $\begin{array}{l}\mathrm{K} / \mathrm{Mg} \text { ratio } \\
\text { in } \\
\text { nutrient } \\
\text { solution }\end{array}$ & $\begin{array}{l}\text { Number } \\
\text { of } \\
\text { ratios }\end{array}$ & $\begin{array}{l}\text { Concentrations } \\
(\mathrm{K}+\mathrm{Mg}) \\
\text { meq/litre }\end{array}$ & $\mathrm{pH}$ & $\begin{array}{l}\text { Number } \\
\text { of } \\
\text { treatments }\end{array}$ & $\begin{array}{l}\text { Number } \\
\text { of } \\
\text { replications }\end{array}$ \\
\hline Yoshida (1964) & $79 \rightarrow 1$ & 7 & $25-5-10-20$ & $4.0-5.0-6.0$ & 84 & 2 \\
\hline $\begin{array}{r}\text { Van der Maarl } \\
(1965)\end{array}$ & $1 \rightarrow 1 / 79$ & 7 & 10 & $4.0-5.0-6.0$ & 21 & 2 \\
\hline Benko (1966) & $499 \rightarrow 1 / 499$ & 31 & 10 & $4.0-6.0$ & 62 & 3 \\
\hline Barel (1968) & $299 \rightarrow 1 / 299$ & 10 & 10 & 6.0 & $40^{*}$ & $3-6$ \\
\hline
\end{tabular}

* 4 weekly harvests.

(Ca, $\mathrm{NO}_{3}, \mathrm{P}, \mathrm{Fe}, \mathrm{SO}_{4}$ constant.)

A correct interpretation of the results of these experiments also met with many difficulties. Therefore, finally, water cultures were chosen for the study of the more specific processes of ion uptake. In water cultures, variations in the composition are easy to make, the different compositions can be easily defined and quite well maintained at constant values during the experimental period. As far as I am concerned, the final experiments on the described disease were carried out by my doctoral student Yoshida (1964), the guest worker Benko (1966) and the students van de Maarl (1965) and Barel (1968). Resuits of their experimental work will be compiled in this paper.

Contrary to Hudig's research work - mainly concentrated on soil conditions - this study, as described in this paper, was aimed at studying the quantitative relationships of different processes governing the uptake of ions by the plant.

The experiments described here were carried out in nutrient solutions with different ratios between potassium and magnesium and studied under different conditions. Table 1 shows the range of factors covered by these experiments.

\section{Formulations}

Different models are used for the formulations of the quantitative relationship between the amounts of absorbed ions and the concentration of the respective ions in the growth medium. This model can be a carrier system (van den Honert, 1937; Epstein \& Hagen, 1952), an adsorption preceding the absorption (Schuffelen \& Loosjes, 1946), or a mechanism, which is not precisely indicated (Epstein, 1972). All these models finally lead to the same mathematical formulation, viz a hyperbolic relationship between the uptake and the concentration in the growth medium. Therefore, the argumentation by use of experimental results is not sufficiently conclusive to arrive at a justified choice of a definite model. However, in the theoretical study of plant nutrient application, the kind of relationship is of more importance than the actual model, so that here only the hyperbolic relationship will be considered without giving priority to a definite model.

This relationship is expressed by the following equation:

$$
\mathrm{di} / \mathrm{dt}=\mathrm{v}=\mathrm{V}_{\max } \cdot \mathrm{bc} /(1+\mathrm{bc})
$$

where $i$ is the amount of absorbed ions, $t$ the period of time, $v$ the rate of absorption, $V_{\max }$ the maximum rate of absorption, $c$ the concentration of the ion in the growth medium and $\mathrm{b}$ a constant connected with the binding energy between the pertinent ion and the 
uptake mechanism substance. The reciprocal value of $\mathbf{b}$ is numerically equal to $\mathrm{k}_{\mathrm{M}}$, the Michaelis-Menten constant from enzymatic equilibria. Eq. 1 is always applied for short term experiments (ranging from (a few) minutes to about 10 hours). Within such a short period no important change takes place in the plant so that the values of $V_{\max }$ and $b$ remain constant. Integration of Eq. 1 leads to

$$
\mathrm{i}=\mathrm{V}_{\max } \cdot \mathrm{t} \cdot \mathrm{bc} /(1+\mathrm{bc})
$$

$\mathrm{V}_{\text {nax }}$ is a function of the amount of plant material taking part in the process of ion absorption. By rough approximation, it can be said that $\mathrm{V}_{\mathrm{mdx}}$ is proportional to the dry weight of the plant $(\Pi)$.

From $\mathrm{V}_{\text {nax }}=\mathrm{K} . \Pi$ it follows that

$$
\begin{aligned}
& \mathrm{i}=\mathrm{K} \cdot I \cdot \mathrm{t} \cdot \mathrm{bc} /(1+\mathrm{bc}), \text { or } \\
& \mathrm{i} / I I=\mathrm{I} \cdot \mathrm{bc} /(1+\mathrm{bc}), \text { where } \mathrm{I}=\mathrm{K} \cdot \mathrm{t}
\end{aligned}
$$

$\mathrm{I}$ is the maximum increase of the content $(\mathrm{i} / I I)$ during the experiment.

In case of continuing experiments the relationship between the increase of content and the concentration is more complicated. Assuming that the equation $\mathrm{V}_{\max }=\mathrm{K} . \Pi$ remains valid during a period of equal physiological behaviour, as in the case in oats, during the initial growth in the first few weeks, the change of $V_{\max }$ or I can be calculated from the changes in the amount of dry maiter.

The following relation exists during the first weeks of plant growth in nutrient solutions with a sufficient supply of side light (Barel, 1968):

$$
\mathrm{d} l I / \mathrm{dt}=a I I
$$

where $\alpha$ is a constant connected with the rate of growth of the plant. Integration leads to

$$
\Pi=H_{\mathrm{o}} \cdot \exp \alpha \mathrm{t}
$$

Substitution of Eq. 4 in Eq. 1 and substituting $\mathrm{V}_{\max }$ by $\mathrm{K} \Pi$ gives

$$
\mathrm{di} / \mathrm{dt}=\mathrm{K} \cdot \Pi_{\mathrm{o}} \cdot \mathrm{e}^{a \mathrm{t}} \cdot \mathrm{bc} /(1+\mathrm{bc})
$$

By integration we obtain

$$
\begin{aligned}
& \mathrm{i}=\mathrm{K} \cdot \Pi_{\mathrm{o}} \cdot \int\left(\mathrm{e}^{\alpha \mathrm{t}} \mathrm{dt}\right) \cdot \mathrm{bc} /(1+\mathrm{bc}), \text { or } \\
& \mathrm{i}=\mathrm{K} \cdot \Pi_{\mathrm{o}} \cdot(1 / \alpha) \cdot \mathrm{e}^{\alpha \mathrm{t}} \cdot \mathrm{bc} /(1+\mathrm{bc}), \text { or } \\
& \mathrm{i} / \Pi=(\mathrm{K} / \alpha) \cdot \mathrm{bc} /(1+\mathrm{bc})
\end{aligned}
$$

From Eq. 4 we obtain

$$
\alpha=\left(\ln \Pi-\ln I_{\mathrm{o}}\right) / \mathrm{t}
$$

Substitution of Eq. 5 gives

$$
\left(\ln \Pi-\ln \Pi_{\mathrm{o}} \cdot \mathrm{i} / \Pi=\mathrm{I} . \mathrm{bc} /(1+\mathrm{bc})\right.
$$

For experiments lasting several weeks, the increase of the content must be corrected for the total amount of plant material.

These general formulas are still incomplete because two aspects have not been taken into account. The first is the difference in electric potential between the root and the growth medium. When this point is taken into consideration, $\mathrm{c}$ must be multiplied by the factor

$$
\mathrm{e}^{-(\mathrm{nF} / \mathrm{RT}) \mathrm{E}}
$$


where $\mathrm{n}$ is the value of the pertinent ion, $\mathrm{F}$ the Faraday, $\mathrm{R}$ the gas constant, $\mathrm{T}$ the absolute temperature and $E$ the difference in electric potential between the root and the growth medium (Schuffelen \& Loosjes, 1946).

The second aspect is that the formula is based on the assumption that the uptake mechanism functions in the same way as it does in enzymatic processes or in the Langmuir approximation for gases. Generally, the processes in which ions are involved must also include ion exchange, which takes place to maintain electroneutrality. Therefore the primary Eq. 1 must be changed into

$$
\mathrm{di}_{1} / \mathrm{dt}=\mathrm{V}_{\max } \cdot \mathrm{b}_{1} \mathrm{c}_{1} /\left(\mathrm{b}_{1} \mathrm{c}_{1}+\mathrm{b}_{2} \mathrm{c}_{2}\right)
$$

where $b_{1}$ and $b_{2}$ are constants and $c_{1}$ and $c_{2}$ the concentrations of the ions 1 and 2 . From the point of view of application, this change does not essentially alter the formula because in experiments one of the ions is usually kept constant.

When mechanisms are studied in which more than two ions are involved the formula is as follows:

$$
\begin{aligned}
& \mathrm{di}_{1} / \mathrm{dt}=\mathrm{V}_{\max } \cdot \mathrm{b}_{1} \mathrm{c}_{1} /\left(\mathrm{b}_{1} \mathrm{c}_{1}+\mathrm{b}_{2} \mathrm{c}_{2} \ldots+\mathrm{b}_{\mathrm{n}} \mathrm{c}_{\mathrm{n}}\right) \\
& \mathrm{di}_{2} / \mathrm{dt}=\mathrm{V}_{\max } \cdot \mathrm{b}_{2} \mathrm{c}_{2} /\left(\mathrm{b}_{1} \mathrm{c}_{1}+\mathrm{b}_{2} \mathrm{c}_{2} \ldots+\mathrm{b}_{\mathrm{n}} \mathrm{c}_{\mathrm{n}}\right)
\end{aligned}
$$

When these equations are changed in the same way as it was done with Eq. 1 it leads to the following:

$$
\begin{aligned}
& \left.\left(\ln \Pi-\ln \Pi_{\mathrm{o}}\right) \cdot \mathrm{i}_{1} / \Pi=\mathbf{I} \cdot \mathrm{b}_{1} \mathrm{c}_{1} / \mathrm{b}_{1} \mathrm{c}_{1}+\mathrm{b}_{2} \mathrm{c}_{2} \ldots+\mathrm{b}_{\mathrm{n}} \mathrm{c}_{\mathrm{n}}\right) \\
& \left(\ln \Pi-\ln \Pi_{\mathrm{o}}\right) \cdot \mathrm{i}_{2} / \Pi=\mathrm{I} \cdot \mathrm{b}_{2} \mathrm{c}_{2} /\left(\mathrm{b}_{1} \mathrm{c}_{1}+\mathrm{b}_{2} \mathrm{c}_{2} \ldots+\mathrm{b}_{\mathrm{n}} \mathrm{c}_{\mathrm{n}}\right) \text {, or } \\
& \mathrm{i}_{1} / \mathrm{i}_{2}=\mathrm{b}_{1} \mathrm{c}_{1} / \mathrm{b}_{2} \mathrm{c}_{2}
\end{aligned}
$$

Now it seems quite probable that there exist at least two mechanisms for the uptake of ions - one highly specific for one particular sort of ions (b has a high value) and already active at very low concentrations of this ion; and another mechanism or a series of mechanisms, which are far less specific and go together with a low value for $b$. This mechanism will be active effectively only at higher concentrations. Due to its low specificity. its activity will affect more than one kind of ions for which it will act as common mechanism. Epstein (1972) uses the terms Mechanism I and Mechanism II. Here preference is given to terms specific and common mechanisms (carriers).

In case of uptake of $K$ and $M g$, three values of $I$ must be discussed, viz $I_{K}, I_{M g}$ and $I_{c}$, which represent the maximum increase of concentration by the specific $K$ mechanism, the specific $\mathrm{Mg}$ mechanism and the common mechanism, respectively.

\section{Experimental results}

\section{Effect of $p H$}

In his thesis Yoshida (1964) mentions the fact that according to his experimental material the effect of $\mathrm{pH}$ on the mottling of leaves and on the uptake of $\mathrm{Mg}$ was extraordinary ions - one highly specific for one particular sort of ions (b has a high value) and already

Only by very low magnesium concentrations a small decrease of the uptake of this ion is observed at low $\mathrm{pH}$ values. This observation contradicts the observations made in field experiments, where the effect of $\mathrm{pH}$ is usually very clear. Two causes can be given for this difference. In the first place, there is a narrow relation between the acidity of the soil and its magnesium content. Low $\mathrm{pH}$ values mostly correspond with low contents of 
Table 2. Average magnesium content in meq/100 $\mathrm{g} \mathrm{d.m.}$

\begin{tabular}{|c|c|c|c|c|c|c|c|c|}
\hline \multirow[t]{3}{*}{$\mathrm{K} / \mathrm{Mg}$ ratio } & \multicolumn{3}{|c|}{ Yoshida } & \multicolumn{3}{|c|}{ van der Maarl } & \multicolumn{2}{|c|}{ Benko } \\
\hline & $\mathrm{pH}$ & $\mathrm{pH}$ & $\mathrm{pH}$ & $\mathrm{pH}$ & $\mathrm{pH}$ & $\mathrm{pH}$ & $\mathrm{pH}$ & $\mathrm{pH}$ \\
\hline & 4.0 & 5.0 & 6.0 & 4.0 & 5.0 & 6.0 & 4.0 & 6.0 \\
\hline $499 \rightarrow 99$ & - & - & - & - & - & - & 1.8 & 2.2 \\
\hline $79 \rightarrow 19$ & 2.3 & 2.5 & 2.5 & - & - & - & 4.2 & 4.2 \\
\hline $14 \rightarrow 1$ & 7.2 & 7.0 & 6.7 & - & - & - & 9.3 & 10.3 \\
\hline $1 \rightarrow 1 / 9$ & - & - & - & 17.1 & 16.0 & 16.7 & 14.3 & 16.1 \\
\hline $1 / 9 \rightarrow 1 / 19$ & - & - & - & - & - & - & 18.7 & 19.0 \\
\hline $1 / 19 \rightarrow 1 / 79$ & - & - & - & 27.2 & 32.3 & 26.6 & 26.2 & 26.8 \\
\hline $1 / 79 \rightarrow 1 / 499$ & - & - & - & - & - & - & 37.0 & 36.8 \\
\hline
\end{tabular}

magnesium in the soil. Secondly, the fact must be taken into consideration that in field experiments the effect of the soil $\mathrm{pH}$ is mostly studied by comparing different levels of lime application. As all the products used for liming, contain small amounts of magnesium (about $1 \%$ ), the increased $\mathrm{pH}$ levels usually correspond with higher $\mathrm{Mg}$ contents of the soil. Usually this fact has been neglected.

\section{Quantification of the mechanisms}

Taking the existence of at least three mechanisms as a starting point, it may be assumed that at a high $\mathrm{K} / \mathrm{Mg}$ ratio in the growth medium, the common mechanism $\left(\mathbf{I}_{c}\right)$ will be fully used for the uptake of potassium. The uptake of magnesium will in this case wholly depend on the action of the specific magnesium mechanism $\left(\mathrm{I}_{\mathrm{Mg}}\right)$. At a low $\mathrm{K} / \mathrm{Mg}$ ratio in the growth medium, the common mechanism will be fully used for the uptake of magnesium, so that the specific potassium mechanism $\left(\mathrm{J}_{\mathrm{K}}\right)$ will be responsible for the total potassium uptake. If the specifically absorbed quantities of $\mathrm{Mg}$ and $\mathrm{K}$, respectively, are expressed as percentages of the total sum of potassium plus magnesium uptake, it will give an indication of the shares of both the specific and the common mechanisms in the total uptake. Table 3 shows the results of this calculation, which of course is only meant as a rough indication. The figures are in full agreement with the fact known in practice that the uptake of magnesium may easily be impeded by an excess of potassium. The share of the specific mechanism for the uptake of magnesium is very small and as a rule not sufficient to satisfy the magnesium requirement of the plant. In general it is assumed

Table 3. Mean proportional distribution of $\mathrm{K}$ - and $\mathrm{Mg}$ uptake between the different mechanisms.

\begin{tabular}{llll}
\hline & $\mathrm{I}_{\mathrm{K}}$ & $\mathrm{I}_{\mathrm{Mg}}$ & $\mathrm{I}_{\mathrm{c}}$ \\
Yoshida & $25^{*}$ & $5.8 ?$ & - \\
Van der Maarl & 35 & - & - \\
Benko & 31 & 2.5 & - \\
Barel & 33 & 3.2 & - \\
Rounded average & 30 & 3 & 67 \\
\hline
\end{tabular}

* Calculated from a short-term experiment. 
Table 4. $\mathrm{K}$ and $\mathrm{Na}$ concentrations (meq/100 $\mathrm{g} \mathrm{d.m.).}$

\begin{tabular}{lrrl}
\hline $\begin{array}{l}\text { K/Mg ratio } \\
\text { in nutrient } \\
\text { solution }\end{array}$ & $\mathrm{K}$ & $\mathrm{Na}$ & $\Sigma(\mathrm{Na}+\mathrm{K})$ \\
& & & \\
$1: 7$ & 156 & 0 & - \\
$1: 29$ & 113 & 3 & - \\
$1: 79$ & 81 & 8 & - \\
$1: 199$ & 44 & 16 & - \\
$1: 299$ & 28 & 16 & 44 \\
$1: 399$ & 24 & 19 & 43 \\
$1: 499$ & 23 & 21 & 44 \\
\hline
\end{tabular}

that mottling of the leaves appears with $\mathrm{Mg}$ contents below $10 \mathrm{meq} / 100 \mathrm{~g}$ of dry matter while reductions of yield may be expected with contents below $8 \mathrm{meq} / 100 \mathrm{~g} \mathrm{~d} . \mathrm{m}$. For $\mathrm{K}$ the lowest limit is usually assumed to be about $20 \mathrm{meq} / 100 \mathrm{~g} \mathrm{~d} . \mathrm{m}$. The total $\mathrm{K}+\mathrm{Mg}$ mechanisms take up about $200 \mathrm{meq} / 100 \mathrm{~g} \mathrm{d.m}$. Assuming a share of $3 \%$ for the $\mathrm{Mg}$ specific mechanism, it would be possible to take up about 6 meq. To prevent an occurrence of a magnesium shortage, a part of the common uptake mechanism must be available for $\mathrm{Mg}$ uptake. In the case of potassium the specific mechanism can take up about 60 meq/ $100 \mathrm{~g} \mathrm{~d}$.m. - a quantity sufficient to prevent potassium deficiency.

\section{Competition between potassium and sodium}

At low ratios of $\mathrm{K} / \mathrm{Mg}$ Benko (1966) found competition between potassium and sodium in the uptake by the specific potassium uptake mechanism. In Table 4 the data are given of this finding. Apparently the specific mechanism is not quite specific at all. However, at a $\mathrm{K} / \mathrm{Mg}$ ratio of $1: 19$ no $\mathrm{Na}$ was absorbed anymore; the $\mathrm{K}$ concentration seems then to be sufficiently high to replace all the $\mathrm{Na}$ from the uptake mechanism. Calculations on the degree of competition between $\mathrm{K}$ and $\mathrm{Na}$ could not be undertaken, because the latter ion was only present in the medium as a contamination and its concentration was not measured.

\section{Competition between potassium and magnesium at the common mechanism}

In the middle of the range of ratios between $\mathrm{K} / \mathrm{Mg}$, for example between $5: 1$ and $1: 5$, it may be assumed that the specific mechanisms will be completely saturated with the respective ions. The extra amount of ions taken up beside the share provided by the specific mechanism may be considered as provided by the common mechanism. In formula

$$
\begin{aligned}
& \mathrm{i}_{\mathrm{K}} / \Pi-\mathrm{I}_{\mathrm{K}}+\mathrm{I}_{\mathrm{c}} \cdot \mathrm{b}_{\mathrm{K}} \mathrm{c}_{\mathrm{K}} /\left(\mathrm{b}_{\mathrm{K}} \mathrm{c}_{\mathrm{K}}+\mathrm{b}_{\left.\mathrm{Mg}_{\mathrm{g}} \mathrm{c}_{\mathrm{g}}\right)}\right. \\
& \mathrm{i}_{\mathrm{Mg}} / \Pi=\mathrm{I}_{\mathrm{Mg}}+\mathrm{I}_{\mathrm{c}} \cdot \mathrm{b}_{\mathrm{Mg}_{\mathrm{Mg}}} /\left(\mathrm{b}_{\mathrm{K}} \mathrm{c}_{\mathrm{K}}+\mathrm{b}_{\mathrm{Mg}_{\mathrm{gg}}}\right) \text {, or } \\
& \left(\mathrm{i}_{\mathrm{K}} / \Pi=\mathrm{I}_{\mathrm{k}}\right) /\left(\mathrm{i}_{\mathrm{Mg}} / / \Pi-\mathrm{I}_{\mathrm{Mg}}\right)=\mathrm{c}_{\mathrm{Mg}} / \mathrm{c}_{\mathrm{K}} \cdot \mathrm{b}_{\mathrm{K}} / \mathrm{b}_{\mathrm{Mg}}
\end{aligned}
$$

This formula provides a means of expressing the relative binding energy $\left(c_{\mathrm{K}} / \mathrm{c}_{\mathrm{Mg}}\right)$ for $\mathrm{K}$ and $\mathrm{Mg}$ of the common mechanism in a relative figure. When the data from Table 3 are used, the following formula is obtained:

$$
\mathrm{b}_{\mathrm{K}} / \mathrm{b}_{\mathrm{Mg}}=\mathrm{c}_{\mathrm{Mg}} / \mathrm{c}_{\mathrm{K}} \cdot\left[\mathrm{i}_{\mathrm{K}}-0.3\left(\mathrm{i}_{\mathrm{K}}+\mathrm{i}_{\mathrm{Mg}_{\mathrm{g}}}\right)\right] /\left[\mathrm{i}_{\mathrm{Mg}_{\mathrm{g}}}-0.03\left(\mathrm{i}_{\mathrm{K}}+\mathrm{i}_{\mathrm{Mg}}\right)\right]
$$


Table 5. Relative binding energy $\left(\mathrm{c}_{\mathrm{K}} / \mathrm{c}_{\mathrm{Mg}}\right)$.

\begin{tabular}{llllll}
\hline K/Mg & Yoshida & $\begin{array}{l}\text { Van der } \\
\text { Maarl }\end{array}$ & Benko & Barel & Average \\
$5: 1$ & - & - & 1.5 & - & \\
$4: 1$ & 3.0 & - & - & - & 1.5 \\
$2: 1$ & 4.3 & - & 2.3 & 4.9 & 3.0 \\
$1: 1$ & 6.9 & 4.4 & 3.8 & - & 5.0 \\
$1: 2$ & - & 6.2 & 6.2 & 7.0 & 6.5 \\
$1: 4$ & - & 10.0 & - & - & 10.0 \\
$1: 5$ & - & - & 12.0 & - & 12.0 \\
\hline
\end{tabular}

Table 5 shows the results of these calculations.

The obtained results do not agree with the given hypothesis of a total of three uptake mechanisms for $\mathrm{K}$ and $\mathrm{Mg}$. In that case a constant ratio of $\mathrm{b}_{\mathrm{K}} / \mathrm{b}_{\mathrm{Mg}}$ should be found for the common part.

Three possibilities can be considered as causes for the inconstancy of this ratio. These are: a possibly difference between the concentration of potassium and magnesium near the root surface and their concentrations in the solution; the effect of the root potential, which has not been accounted for; and the fact that not only three but more mechanisms are involved in the uptake of these ions.

$\mathrm{Bij}$ a decreasing $\mathrm{K} / \mathrm{Mg}$ ratio in solution, the supply of $\mathrm{K}$ by $\mathrm{K}$ flux will be lowered and that of $\mathrm{Mg}$ increased so that the ratio between the ions $\left(\mathrm{c}_{\mathrm{K}} / \mathrm{c}_{\mathrm{Mg}}\right)$ near the root will be lower than in the rest of the solution. If a corresponding correction is introduced in the data of Table 5, the data from top to bottom would have to be multiplied by more and more decreasing figures, which would have a converging effect on them. As the extent of this correction cannot be quantitatively assessed, it is not known whether the same values would be obtained.

The effect of the root potential can be calculated with some approximation. By choosing herefore the maximum effect of the $\mathrm{K}$ concentration in the medium on the root potential ( $1 \mathrm{pK}$ unit corresponds with $58 \mathrm{mV}$ ), values for the ratio of binding energy are obtained, which are nearly identical in the middle of the range (Table 6). If experimentally established data for K-Mg solutions as determined by Grobler (1959) are chosen, the effect of the correction is less but still considerable (Table 6). A quantitative statement can neither be given here.

Finally, there is scope for discussion about the third possibility. This possibility has already been considered by Epstein \& Rains (1965) with regard to an explanation of their experimentally found data.

Table 6. Corrected binding energy $\left(\mathrm{c}_{\mathrm{K}} / \mathrm{c}_{\mathrm{Mg}} \cdot \exp -(\mathrm{NF} / \mathrm{RT}) \mathrm{E}\right)$

\begin{tabular}{lllllllc}
\hline & \multicolumn{7}{l}{ K/Mg } \\
\cline { 2 - 7 } & $5: 1$ & $4: 1$ & $2: 1$ & $1: 1$ & $1: 2$ & $1: 4$ & $1: 5$ \\
Mean & 1.5 & 3.0 & 3.8 & 5.0 & 6.5 & 10.0 & 12.0 \\
Theor. correction & 2.5 & 5.1 & 5.1 & 5.0 & 4.4 & 5.5 & 5.5 \\
Grobler correction & 2.4 & 4.3 & 4.8 & 5.0 & 5.5 & 7.9 & 8.9 \\
\hline
\end{tabular}


The experiments do not make possible a positive and clear statement. More accurate and numerous measurements will have to be made with a special attention to the concentrations near the root surface and the root potential.

\section{References}

Barel, D., 1968. Een onderzoek naar het verloop van de kalium en magnesiumabsorptie door haver met de tijd. Verslag doctoraal onderzoek.

Benko, V., 1966. Einfluss der Verschiedene Verhältnisse von Kalium und Magnesium auf den Ertrag der Trockensubstanz und Ionenaufnahme bei Hafer (Avena sativa, var. Marne). Rapport.

Epstein, E., 1972. Mineral nutrition of plants; principles and perspectives. New York.

Epstein, E. \& C. E. Hagen, 1952. A kinetic study of the absorption of alkali cations by barley roots. Pl. Physiol. 27: 457-474.

Epstein, E. \& D. W. Rains, 1965. Carrier-medicted cation transport in barley roots. Kinctic evidence for a spectrum of active sites. Proc. Natn. Acad. Sci. 53: 1320-1324.

Grobler, J. H., 1959. Initial phase ion uptake by plant roots and the interpretation of root potentials. Thesis, Wageningen.

Honert, T. H. van den, 1937. Over eigenschappen van plantenwortels, welke een rol spelen bij de opname van voedingszouten. Natuurk. Tijdschr. Ned.-Ind. 97: 150-162.

Hudig, J. \& J. Jonker, 1916. De resultaten van de bemestingsproeven op Hooghalensch zieke grond te Spitsbergen. Landbouwcourant van de Noord Ooster, 23 nov.

Maarl, J. van der, 1965 . Onderzoek betreffende het verband tussen de $\mathrm{K}$ en $\mathrm{Mg}$ opname bij haver. Verslag doctoraal onderzoek.

Schuffelen, A. C., 1940. Is de plantengroei afhankelijk van de ionenverhouding in de grond. II. De ionverhouding in den grond en de rendabiliteit der meststoffen. Landbouwk. Tijdschr. 52: 845-868.

Schuffelen, A. C. \& R. Loosjes, 1946. The importance of the ion activity of the merlium and the root potential for the cation absorption by the plant. Proc. Kon. ned. Akad. Wer. (Amsterdam) 49: $80-86$.

Yoshida, F., 1964. Interrelationships between potassium and magnesium absorptic n by oats (Avena sativa $\mathbf{L}$.). Thesis, Wageningen. 